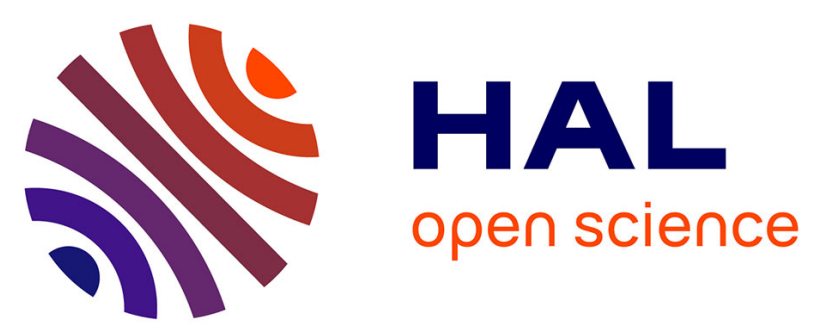

\title{
Extracorporeal circulation during on-pump cardiac surgery: an evaluation of the Energy Equivalent Pressure (EEP) index based on waveforms decomposition in harmonics
}

\author{
Agnès Drochon, Olivier Fouquet, Christophe Baufreton
}

\section{To cite this version:}

Agnès Drochon, Olivier Fouquet, Christophe Baufreton. Extracorporeal circulation during on-pump cardiac surgery: an evaluation of the Energy Equivalent Pressure (EEP) index based on waveforms decomposition in harmonics. Artificial Organs, 2021, 45, pp.861-865. 10.1111/aor.13928 . hal03146553

\section{HAL Id: hal-03146553 \\ https://hal.utc.fr/hal-03146553}

Submitted on 19 Feb 2021

HAL is a multi-disciplinary open access archive for the deposit and dissemination of scientific research documents, whether they are published or not. The documents may come from teaching and research institutions in France or abroad, or from public or private research centers.
L'archive ouverte pluridisciplinaire HAL, est destinée au dépôt et à la diffusion de documents scientifiques de niveau recherche, publiés ou non, émanant des établissements d'enseignement et de recherche français ou étrangers, des laboratoires publics ou privés. 


\title{
Extracorporeal circulation during on-pump cardiac surgery: an evaluation of the Energy Equivalent Pressure (EEP) index based on waveforms decomposition in harmonics
}

\author{
Agnès Drochon $^{1 *}$, Olivier Fouquet ${ }^{2}$, Christophe Baufreton $^{2}$
}

1 CNRS, University of Bordeaux, Arts et Metiers Institute of Technology, Bordeaux INP, INRAE, I2M Bordeaux, F-33400 Talence, France

${ }^{2}$ Department of Cardio-Thoracic Surgery, University-Hospital Angers, 4, rue Larrey 49100 Angers France

*Corresponding author: agnes.drochon@u-bordeaux.fr

Mails of the co-authors: OlFouquet@chu-angers.fr $;$ ChBaufreton@chu-angers.fr

Accepted in: Artificial Organs, 2021. https://doi.org/10.1111/aor.13928

\begin{abstract}
:
The use of pulsatile perfusion (PP) instead of Non-Pulsatile Perfusion (NP) during cardiopulmonary bypass (CPB) continues to be a source of debate. The disagreements among the conclusions of the published studies may be due to different factors: differences in the type of patients included in the studies, differences in the protocol of the studies and difficulty to quantify the pulsatility of the flow. In the present paper, we propose a quantitative evaluation of Shepard's EEP index, based on the harmonic decomposition of the physiological aortic pressure and flow rate signal. It is thus demonstrated that the surplus energy provided by pulsatile flow remains moderate (of order $10 \mathrm{mmHg}$ ), but that it can be improved by changing the relative shapes of the pressure and flow waves.
\end{abstract}

Keywords: cardiac surgery, extra-corporeal circulation, Energy Equivalent Pressure, pulsatile flow

The use of pulsatile perfusion (PP) instead of Non-Pulsatile Perfusion (NP) during cardiopulmonary bypass (CPB) continues to be a source of debate.

Many papers conclude that pulsatile flow significantly improves blood flow of the vital organs (brain, heart, liver, pancreas), reduces the systemic inflammatory response syndrome, decreases the incidence of postoperative deaths of the patients (1). Pulsatile flow has been reported to improve microvascular perfusion (i.e. to decrease peripheral resistance) (2-6).

However, previous generations of pulsatile pumps had also some disadvantages: complicated to operate, 
increase the risk of hemolysis and the risk of turbulence, especially in the near field of the canula. The maximum blood velocities and shear stresses in the vessels are also enhanced in the case of pulsatile perfusion $(7,8)$. In addition, these pumps were expensive and difficult to sterilize, and they did not reproduce the exact physiological flow pattern. Consequently, as it is mentioned in the recent "2019 EACTS/EACTA/EBCP guidelines on cardiopulmonary bypass in adult cardiac surgery" (9), all over the world, the majority of CPB procedures are run with a continuous flow (with roller or centrifugal pumps).

Moreover, some groups conclude that pulse is unnecessary, and that efforts to optimise pulsatility are not justified (10). Elbers et al. (11) used sidestream dark-field imaging to record video clips of the sublingual human microcirculation. Although the pulse pressure was higher during pulsatile perfusion, they found that the perfused vessel density did not differ between nonpulsatile and pulsatile perfusion. They concluded that there is no obvious relationship between pulse pressure and microcirculatory parameters.

The disagreements among the conclusions of all these studies may be due to different factors: differences in the type of patients included in the studies, differences in the protocol of the studies (for example, the duration of perfusion or the delay of observation (12)), influence of the components of the extra-corporeal circuit (other than the pump: oxygenator, cannulae and their position (13), tubing (14), ...), and difficulty to quantify the pulsatility of the flow.

Some classical indexes used to describe the pressure or flow pulse are recalled in the paper of Voss et al. (10). Among these quantities, they quote the EEP (Energy Equivalent Pressure), proposed by Shepard et al. (15) in order to quantify and compare the energy of pulsatile and non-pulsatile blood flow. EEP can be obtained from pressure $\mathrm{p}(\mathrm{t})$ and flow $\mathrm{q}(\mathrm{t})$ waveforms and is defined as follows:

$$
E E P=\frac{\int p(t) q(t) d t}{\int q(t) d t}
$$

It represents the work done in one cycle of the pulsatile flow divided by the volume of fluid moved during that cycle. In pulsatile flow, EEP is supposed to be larger than the mean pressure but if there is no pulsatility, it will be equal to the mean pressure. The intuition of Shepard was that a pulsatile arterial wave dissipates significantly more utilizable energy to the tissues than does a non-pulsatile wave of the same mean pressure. The hemodynamic parameter EEP has also been used recently to quantify the pulsatility of flow in some decellularization experiments (16).

In 1985, Wright and Furness (17) suggested that it was necessary to define more precisely what is pulsatile 
flow. They explained that some types of pulsatile flows are more effective than others in preserving tissue function. In order to describe more precisely the morphology of the flow or pressure waveforms, they recommended to use the harmonic wave decomposition. This mathematical theory was established by Fourier and shows that a signal of any shape, $\mathrm{s}(\mathrm{t})$, can be transformed to a mean level plus a series of sine waves of differing amplitude, frequency and phase (the harmonics). The harmonic frequencies are multiples of the fundamental wave frequency. For a heart rate of 60 beats/min, the fundamental frequency is $1 \mathrm{~Hz}$, the second harmonic is $2 \mathrm{~Hz}$, and so forth. At zero frequency, impedance is equivalent to resistance in the steady-flow state.

The phase differences between pressure and flow are caused by compliance and inertance in the vascular system, and these compliance and inertance allow energy storage and transmission.

In order to go further, in the present paper, we propose a quantitative evaluation of Shepard's EEP index, based on the harmonic decomposition of $\mathrm{q}(\mathrm{t})$ and $\mathrm{p}(\mathrm{t})$.

\section{MATERIALS and METHODS}

Simultaneous data of pressure and flow from the ascending aorta in three patients undergoing cardiac surgery are available in Patel et al. (18). The Fourier series calculated from the aortic pressure and flow curves are recalled here, in Table 1. The three Patients are called: "CH", "DC", and "LF". The series are limited to the ten first terms. This is actually enough, because the important signal information is contained in the first harmonics.

Let us write the flow rate $\mathrm{q}(\mathrm{t})$ as:

$$
q(t)=q_{0}+\sum_{k=1}^{10} q_{k} \sin \left(2 \pi f k t+\theta_{k}\right)
$$

and the pressure $\mathrm{p}(\mathrm{t})$ as:

$$
p(t)=p_{0}+\sum_{i=1}^{10} p_{i} \sin \left(2 \pi f i t+\emptyset_{i}\right)
$$

where $\mathrm{q}_{0}$ and $\mathrm{p}_{0}$ are the constant term (harmonic "zero", with frequency zero (no time dependency)) for the flow and pressure, $\mathrm{q}_{\mathrm{k}}$ and $\mathrm{p}_{\mathrm{i}}$ are the amplitude of the harmonic " $\mathrm{k}$ " or " $\mathrm{i}$ ", $\theta_{\mathrm{k}}$ and $\phi_{\mathrm{i}}$ are the phase angles, and $\mathrm{f}$ denotes the cardiac frequency. Note that $\mathrm{q}_{0}$ and $\mathrm{p}_{0}$ are also the mean values of the flow and pressure signals over each cardiac cycle.

Multiplying term by term $q(\mathrm{t})$ by $\mathrm{p}(\mathrm{t})$, and integrating this quantity, EEP turns out to be:

$$
E E P=p_{0}+\frac{p_{1}}{2} \frac{q_{1}}{q_{0}} \cos \left(\emptyset_{1}-\theta_{1}\right)+\cdots+\frac{p_{j}}{2} \frac{q_{j}}{q_{0}} \cos \left(\emptyset_{j}-\theta_{j}\right)+\cdots+\frac{p_{10}}{2} \frac{q_{10}}{q_{0}} \cos \left(\emptyset_{10}-\theta_{10}\right)
$$


The data of Patel et al. (18) that we have used for our calculation are re-called in Table 1.

\section{RESULTS}

The flow rates obtained using Eq. (2) and the numerical data given in Table 1 are shown in Fig. 1, for each Patient and for 3 cardiac cycles. The same type of curves are shown in Fig.2 for the pressures (obtained using Eq.(3)). They are quite similar to the instantaneous pressure and flow contours recorded from the ascending aorta and reproduced in the paper of Patel et al. (18). These data can thus be used through Eq. (4) for some reliable calculations of the EEP index.

The values obtained for EEP, along with the mean values of pressure over a cardiac cycle, and the relative percentage of increase are gathered in Table 2. These results demonstrate that the energy surplus due to the pulsatility remains lower than $17 \%$ in any case.

\section{DISCUSSION and CONCLUSION}

Our EEP calculations show that the surplus energy provided by pulsatile flow remains moderate (of order 10 $\mathrm{mmHg}$ ). This result is in agreement with the study of Durr et al. (14), who compared different tubings (more or less compliant) and different aortic models with physiological and sub-physiological compliance. They found that the surplus of energy is better when the tubings or vessels are less compliant, but in any case, it remains lower than $14 \%$ of mean arterial pressure. An order of magnitude of $10 \%$ is also given by Wright (19). The question is then: could this amount be sufficient to propel pulsatility beyond the arterioles?

The increase in EEP values found in the case of pulsatile flow has been related by several groups to some improvement in the microcirculation (better flow of lymph, interstitial fluid, better flow of blood in the capillaries, less microvessels shunting or collapse, ...). A reduction in peripheral vascular resistance may thus be associated with pulsatile perfusion. One of the future direction of our work will be to test the sensitivity of the EEP index to the value of the peripheral resistance through a classical circulatory model. Indeed, the "2019 Guidelines on CBP” (9) recommend to use arterial vasodilators if the patient's mean arterial pressure is higher than $80 \mathrm{mmHg}$ (or vasoconstrictors if mean pressure $<50 \mathrm{mmHg}$ ). Vasodilators will decrease the peripheral resistance and, on the contrary, vasoconstrictors will increase it. This confirms the importance of this parameter, and of the mechanisms of mecanotransduction: conversion of the mechanical forces (shear forces exerted on the walls of the vessels, and radial deformations due to the propagation of the pressure and flow pulses) into biological signals (20). Theoretical studies of sinusoidal blood flow in deformable vessels 
prove that the radial deformation of the vessel is directly related to the flow rate $(21,22)$.

In addition, it is important to mention that the pulsatile power outputs of some "pulsatile pumps" are small compared with those of the human heart. It should be interesting to capture the flow and pressure curves just at the exit of the pump and calculate EEP in order to compare it with EEP obtained with physiological data. Equation 4 demonstrates that the EEP value depends on : i) the moduli of pressure harmonics $\left(\mathrm{p}_{\mathrm{i}}\right)$, that remain rather small, ii) the ratios $\left(\mathrm{q}_{\mathrm{k}} / \mathrm{q}_{0}\right)$ of the moduli of the flow rate harmonics to the mean flow rate, iii) the phase lag between pressure wave and flow wave $\left(\Phi_{\mathrm{j}}-\theta_{\mathrm{j}}\right)$. Consequently, a possible way to increase the value of EEP at the exit of an artificial flow device could be to adjust conveniently the ratios $\left(\mathrm{q}_{\mathrm{k}} / \mathrm{q}_{0}\right)$, and /or the phase lag $\left(\Phi_{\mathrm{j}}-\theta_{\mathrm{j}}\right)$.

In the particular context of extra-corporeal circulation, one has to consider also the damping effect of several components (oxygenator, aortic cannula, arterial filters, ...) and the difficulty to quantify the amount of pulsatile energy lost in these components (10). A study from Lim et al. (23) indicates that up to $80 \%$ of the total hemodynamic energy generated by a pulsatile pump is absorbed by the components of the extra-corporeal circuit and only a small proportion of the pulsatile energy is delivered to the patient. The influence of the aortic compliance and the possible mismatch between cannula and aorta would have to be more carefully studied. This point was already mentioned in the Editorial of Wright and Furness (17). They explained that the arterial line and the cannula can considerably modify the pulse. As demonstrated in several publications from the group of A. Undar (24), reducing the energy lost in the circuit requires to reduce all the pressure drops (linear or singular).

\section{CONFLICT OF INTEREST}

The authors declare that there is no conflict of interest, financial or otherwise.

\section{REFERENCES}

1. Ji B., Undar A. An evaluation of the benefits of pulsatile versus nonpulsatile perfusion during cardiopulmonary bypass procedures in pediatric and adult cardiac patients (Review Paper). ASAIO Journal 2006; 52: 357-361.

2. Taylor K.M. Why pulsatile flow during cardiopulmonary bypass? In: "Towards safer cardiac surgery", 1981, Longmore D.B. Eds, Springer, Dordrecht. 
3. Koning N., Vonk A., Van Barneveld L., Beishuizen A., Van den Brom C., Boer C. Pulsatile flow during cardiopulmonary bypass preserves postoperative microcirculatory perfusion. Eur. Jour. Anaesthesiology 2011; 28:65.

4. O’Neil M., Fleming J., Badhwar A., Guo L. Pulsatile versus nonpulsatile flow during cardiopulmonary bypass: microcirculatory and systemic effects. The Annals of Thoracic Surgery 2012; 94(6): 2046-2053.

5. O’Neil M., Alie R., Guo L., Myers M., Murkin J., Ellis Ch. Microvascular responsiveness to pulsatile and non-pulsatile flow during cardiopulmonary bypass. The Annals of Thoracic Surgery 2018; 105: 1745-1753.

6. Hoefeijzers M., Horst L., Koning N., Vonk A., Boer Ch., Elbers P. The pulsatile perfusion debate in cardiac surgery: answers from the microcirculation? (Review Paper). Jour. of CardioThoracic and Vascular Anesthesia 2015; 29(3): 761-767.

7. Assmann A., Benim A., Gül F., Lux P., Akhyari P., Boeken U., Joos F., Feindt P., Lichtenberg A. Pulsatile extracorporeal circulation during on-pump cardiac surgery enhances aortic wall shear stress. $J$. Biomech. 2012; 45(1): 156-163.

8. Benim A., Nahavandi A., Assmann A., Schubert D., Feindt P., Suh S. Simulation of blood flow in human aorta with emphasis on outlet boundary conditions Appl. Mathematical Modelling 2011; 35: 3175-3188.

9. Wahba A., Milojevic M., Boer Ch., De Somer F., Gudbjartsson T., Van Den Goor J., Jones T., Lomivorotov V., Merkle F., Ranucci M., Kunst G., Puis L. 2019 EACTS/EACTA/EBCP guidelines on cardiopulmonary bypass in adult cardiac surgery Eur. Jour. Cardio-Thor Surg. 2020; 57(2): 210-251.

10. Voss B., Krane M., Jung Ch., Brockmann G., Braun S., Günther T., Lange R., Bauernschmitt R. Cardiopulmonary bypass with physiological flow and pressure curves: pulse is unnecessary! Eur. Jour. Cardio-Thoracic Surgery 2010; 37(1): 223-232. 
11. Elbers P., Wijbenga J., Solinger F., Yilmaz A., Van Iterson M., Van Dongen E., Ince C. Direct observation of the human microcirculation during cardiopulmonary bypass: effects of pulsatile perfusion. Jour. of Cardiothoracic and Vascular Anesthesia 2011; 25(2): 250-255.

12. Koning N., Atasever B., Vonk A., Boer Ch. The effects of pulsatile cardiopulmonary bypass on microcirculatory perfusion: perspectives from a null-result study. Jour. CardioThoracic and Vascular Anesthesia 2011; 25(4): e24.

13. Ahn C., Lee S., Choi C., Park C., Park K., Lee J., Son K. Feasibility of a 3D printed patient-specific model system to determine hemodynamic energy delivery during extra-corporeal circulation ASAIO Jour. 2018; 64 (3): 309-317.

14. Durr A., Kunert A., Albrecht G., Liebold A., Hoenicka M. Hemodynamic energy during pulsatile extracorporeal circulation using flexible and rigid arterial tubing: a reassessment. Perfusion 2019; 34(4): 297-302.

15. Shepard R.B., Simpson D.C., Sharp J.F. Energy Equivalent Pressure. Arch. Surg. 1966; 93(5): 730-740.

16. Park S.M., Yang S., Rye S.M., Choi S. W. Effect of pulsatile flow perfusion on decellularization. BioMedical Engineering OnLine 2018; 10 pages.

17. Wright G. and Furness A. What is pulsatile flow? The Annals of Thoracic Surgery 1985; 39(5): 401-402.

18. Patel D., Greenfield J., Austen W., Morrow A., Fry D. Pressure-flow relationships in the ascending aorta and femoral artery of man. Jour. Appl. Physiol. 1965; 20(3): 459-463.

19. Wright G. Hemodynamic analysis could resolve the pulsatile blood flow controversy. Ann. Thorac. Surg. $1994 ; 58: 1199-1204$. 
20. Pinaud F., Loufrani L., Toutain B., Lambert D., Vandekerckhove L., Henrion D., Baufreton Ch. In vitro protection of vascular function from oxidative stress and inflammation by pulsatility in resistance arteries. The Jour. Thor. Cardio Vasc. Surg. 2011; 142 (5): 1254-1262.

21. Drochon A. Sinusoïdal flow of blood in a cylindrical deformable vessel exposed to an external magnetic field. Eur. Phys. Jour. Appl. Phys. 2016; 73:31101.

22. Womersley J. Oscillatory motion of a viscous liquid in a thin-walled elastic tube: I. The linear approximation for long waves. J. Phil. Mag.1955; 46, 199-221.

23. Lim C.H., Yang S., Choi J.W., Sun K. Optimizing the circuit of a pulsatile extracorporeal life support system in terms of energy equivalent pressure and surplus hemodynamic energy. Artificial Organs 2009; 33(11): 1015-1020.

24. Undar A.; Frazier O.H.; Fraser Ch. Defining pulsatile perfusion: quantification in terms of energy equivalent pressure. Artificial Organs 1999; 23 (8): 712-716. 


\section{TABLES}

TABLE 1. Data from Patel et (18) used for our calculation.

The flow rates $q_{k}$ are in $\mathrm{ml} / \mathrm{s}$, the pressures $p_{i}$ in $\mathrm{mmHg}$, and the phase angles $\theta_{k}$ and $\phi_{i}$ in degrees.

\begin{tabular}{|c|c|c|c|c|c|}
\hline \multirow{2}{*}{\multicolumn{2}{|c|}{$\begin{array}{c}\text { Patient "CH" } \\
\mathrm{f}=1.25 \mathrm{~s}^{-1}\end{array}$}} & \multicolumn{2}{|c|}{ Patient "DC" } & \multicolumn{2}{|c|}{ Patient "LF" } \\
\hline & & $f=1$ & $7 \mathrm{~s}^{-1}$ & $f=$ & $\mathrm{s}^{-1}$ \\
\hline $\mathrm{q}_{0}=67$ & $\mathrm{p}_{0}=94$ & $\mathrm{q}_{0}=84$ & $\mathrm{p}_{0}=96$ & $\mathrm{q}_{0}=65$ & $\mathrm{p}_{0}=74$ \\
\hline $\mathrm{q}_{1}=120$ & $\mathrm{p}_{1}=14$ & $\mathrm{q}_{1}=137$ & $\mathrm{p}_{1}=14.4$ & $\mathrm{q}_{1}=135$ & $\mathrm{p}_{1}=15.2$ \\
\hline$\theta_{1}=9$ & $\phi_{1}=311$ & $\theta_{1}=22$ & $\phi_{1}=319$ & $\theta_{1}=6$ & $\phi_{1}=305$ \\
\hline $\mathrm{q}_{2}=88$ & $\mathrm{p}_{2}=4.9$ & $\mathrm{q}_{2}=104$ & $\mathrm{p}_{2}=4.8$ & $\mathrm{q}_{2}=93$ & $\mathrm{p}_{2}=5.8$ \\
\hline$\theta_{2}=289$ & $\phi_{2}=258$ & $\theta_{2}=315$ & $\phi_{2}=271$ & $\theta_{2}=280$ & $\phi_{2}=241$ \\
\hline $\mathrm{q}_{3}=45$ & $\mathrm{p}_{3}=2.4$ & $\mathrm{q}_{3}=36$ & $\mathrm{p}_{3}=1.8$ & $\mathrm{q}_{3}=37$ & $\mathrm{p}_{3}=2.9$ \\
\hline$\theta_{3}=208$ & $\phi_{3}=212$ & $\theta_{3}=278$ & $\phi_{3}=270$ & $\theta_{3}=200$ & $\phi_{3}=197$ \\
\hline $\mathrm{q}_{4}=8$ & $\mathrm{p}_{4}=0.8$ & $\mathrm{q}_{4}=18$ & $\mathrm{p}_{4}=1.7$ & $\mathrm{q}_{4}=16$ & $\mathrm{p}_{4}=1.7$ \\
\hline$\theta_{4}=161$ & $\phi_{4}=212$ & $\theta_{4}=284$ & $\phi_{4}=277$ & $\theta_{4}=202$ & $\phi_{4}=185$ \\
\hline $\mathrm{q}_{5}=18$ & $\mathrm{p}_{5}=1.5$ & $\mathrm{q}_{5}=25$ & $\mathrm{p}_{5}=2.2$ & $\mathrm{q}_{5}=21$ & $\mathrm{p}_{5}=1.9$ \\
\hline$\theta_{5}=185$ & $\phi_{5}=197$ & $\theta_{5}=217$ & $\phi_{5}=217$ & $\theta_{5}=148$ & $\phi_{5}=125$ \\
\hline$q_{6}=17$ & $\mathrm{p}_{6}=1.4$ & $\mathrm{q}_{6}=5$ & $\mathrm{p}_{6}=0.8$ & $\mathrm{q}_{6}=12$ & $\mathrm{p}_{6}=0.9$ \\
\hline$\theta_{6}=99$ & $\phi_{6}=96$ & $\theta_{6}=204$ & $\phi_{6}=133$ & $\theta_{6}=66$ & $\phi_{6}=41$ \\
\hline $\mathrm{q}_{7}=5$ & $\mathrm{p}_{7}=0.5$ & $\mathrm{q}_{7}=6$ & $\mathrm{p}_{7}=0.7$ & $\mathrm{q}_{7}=7$ & $\mathrm{p}_{7}=0.5$ \\
\hline$\theta_{7}=347$ & $\phi_{7}=325$ & $\theta_{7}=207$ & $\phi_{7}=228$ & $\theta_{7}=83$ & $\phi_{7}=115$ \\
\hline $\mathrm{q}_{8}=6$ & $\mathrm{p}_{8}=0.8$ & $\mathrm{q}_{8}=16$ & $\mathrm{p}_{8}=0.8$ & $\mathrm{q}_{8}=11$ & $\mathrm{p}_{8}=1.1$ \\
\hline$\theta_{8}=109$ & $\phi_{8}=140$ & $\theta_{8}=142$ & $\phi_{8}=168$ & $\theta_{8}=20$ & $\phi_{8}=8$ \\
\hline $\mathrm{q}_{9}=8$ & $\mathrm{p}_{9}=0.8$ & $\mathrm{q}_{9}=3$ & $\mathrm{p}_{9}=0.04$ & $\mathrm{q}_{9}=6$ & $\mathrm{p}_{9}=0.6$ \\
\hline$\theta_{9}=356$ & $\phi_{9}=5$ & $\theta_{9}=104$ & $\phi_{9}=129$ & $\theta_{9}=295$ & $\phi_{9}=260$ \\
\hline $\mathrm{q}_{10}=4$ & $\mathrm{p}_{10}=0.3$ & $\mathrm{q}_{10}=10$ & $\mathrm{p}_{10}=0.8$ & $\mathrm{q}_{10}=2$ & $\mathrm{p}_{10}=0.3$ \\
\hline$\theta_{10}=223$ & $\phi_{10}=214$ & $\theta_{10}=165$ & $\phi_{10}=174$ & $\theta_{10}=41$ & $\phi_{10}=325$ \\
\hline
\end{tabular}


TABLE 2. EEP values, for the 3 Patients. The percentage of increase is: (EEP-Mean Pressure)/Mean Pressure.

\begin{tabular}{|c|c|c|c|}
\hline Patient & $\mathrm{CH}$ & $\mathrm{DC}$ & LF \\
\hline EEP $(\mathrm{mmHg})$ & 104.7 & 104.5 & 86.4 \\
\hline Mean Pres. $(\mathrm{mmHg})$ & 94 & 96 & 74 \\
\hline$\%$ increase & 11.4 & 8.8 & 16.7 \\
\hline
\end{tabular}

\section{FIGURES :}

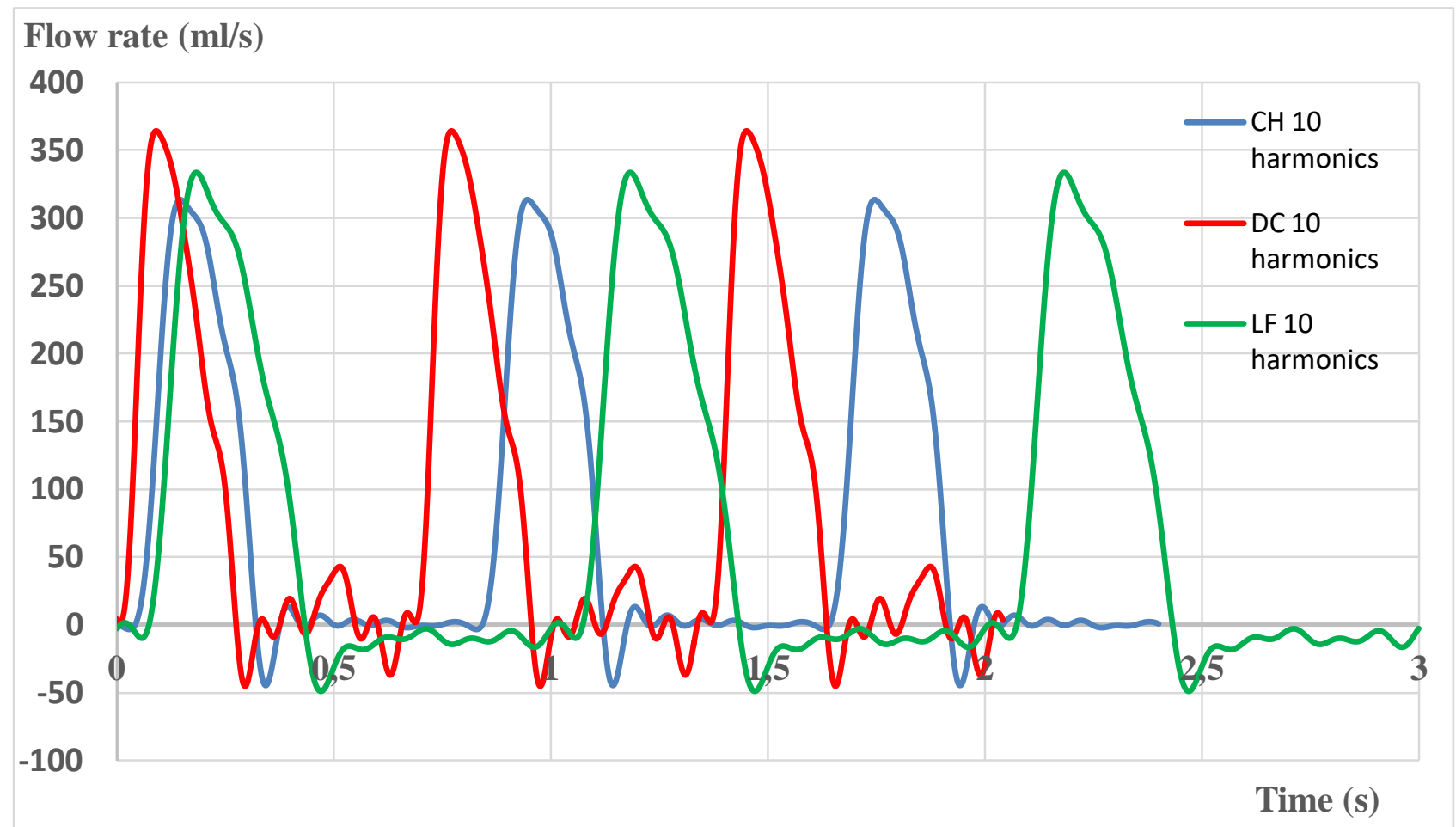

FIG.1 - Flow rates obtained using Equ. (2) and the numerical data given in Table 1 for each Patient and for 3 cycles 


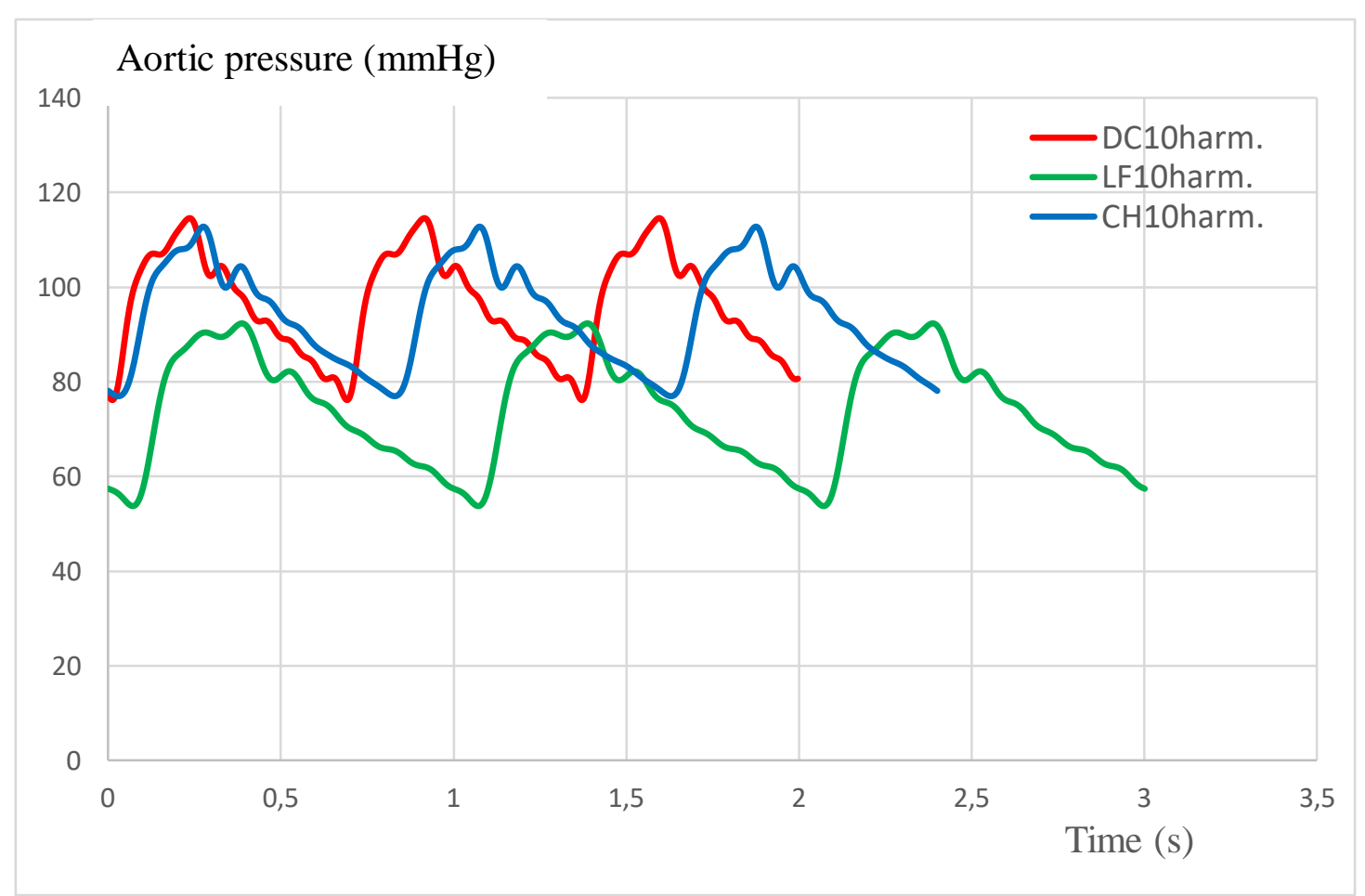

FIG. 2 - Pressure curves obtained using Equ.(3) and the numerical data given in Table 1, for each Patient and for 3 cycles. 